\title{
Análise da Revisão Cochrane: Biomarcadores em Testes Rápidos para Guiar a Prescrição de Antibióticos em Doentes com Infecções Respiratórias Agudas nos Cuidados de Saúde Primários. Cochrane Database Syst Rev. 2014,11:CD010130
}

\author{
Analysis of the Cochrane Review: Biomarkers as Point-Of-Care Tests to Guide \\ Prescription of Antibiotics in Patients with Acute Respiratory Infections in \\ Primary Care. Cochrane Database Syst Rev. 2014,11:CD10130
}

Pedro AZEVEDO ${ }^{1}$, João COSTA ${ }^{1,2,3}$, António VAZ-CARNEIRO ${ }^{1,2}$

Acta Med Port 2014 Nov-Dec;27(6):677-680

\section{RESUMO}

As infecções respiratórias agudas são o motivo mais frequente de prescrição de antibióticos nos cuidados de saúde primários. Uma vez que a maioria das infecções respiratórias agudas têm etiologia viral ou bacteriana não-grave, a utilização de antibióticos não é benéfica e expõe os doentes a efeitos colaterais da terapêutica. Além disso, a prescrição indiferenciada deste grupo farmacológico está relacionada com resistências aos antibióticos promovendo: 1. aumento dos custos para os sistemas de saúde; 2 . ineficácia de tratamentos futuros, aumentado morbimortalidade por doenças infecciosas. No contexto clínico apropriado, o uso de biomarcadores em testes rápidos que permitam avaliar a resposta de fase aguda à lesão de tecido/órgão, é uma estratégia na gestão da terapêutica de doentes com infecções respiratórias agudas em contexto ambulatório. A presente revisão da Cochrane compara a prescrição de antibióticos para infecções respiratórias agudas em ambulatório baseado: 1. exclusivamente na clínica; 2 . no uso de biomarcadores em teste rápido (p.ex. proteína C-reactiva). A proteína C-reactiva em teste rápido parece estar associada à redução do uso de antibióticos, contudo, não se assistiu a uma redução dos dias de tratamento nem da percepção da rapidez de recuperação pelo doente. Poderá haver um aumento de internamentos em comparação com o grupo de doentes tratados sem o recurso ao biomarcador; a mortalidade foi nula em ambos os grupos.

Palavras-chave: Cuidados de Saúde Primários; Infecções Respiratórias; Marcadores Biológicos; Revisão Sistemática.

\section{ABSTRACT}

Acute respiratory infections are the most frequent reason for prescribing antibiotics in primary health care. Since most acute respiratory infections are of viral or non-severe bacterial etiology, the use of antibiotics is not beneficial and exposes patients to side effects. In addition, the undifferentiated prescription of this drug group increases antibiotic resistance and promotes: 1. increased costs for health systems; 2 . failure to future treatments, increased morbidity and mortality from infectious diseases. In the appropriate clinical setting, the use of biomarkers as point-of-care tests to assess the acute phase response to injury of tissue / organ, is a strategy in the therapeutic management of patients with acute respiratory infections in outpatient context. This Cochrane review compared the prescription of antibiotics to acute respiratory infections based: 1 . exclusively in the clinic; 2 . linn the use of biomarkers as point-of-care tests (eg C-reactive protein). The C-reactive protein in quick test seems to be associated with reduced use of antibiotics, however, there has not been a reduction in the lenght of treatment or the perception of recovery by the patient. There may be an increase of hospitalizations compared with the group of patients without the biomarker use; no mortality was register in either group.

Keywords: Primary Health Care; Respiratory Tract Infections; Biological Markers; Systematic Reviews; Anti-Bacterial Agents.

\section{QUESTÃO CLÍNICA}

$\mathrm{O}$ uso de um biomarcador em teste rápido que guie a prescrição antibiótica nas infecções respiratórias agudas (IRA), em ambulatório, reduz a morbimortalidade associada a essa patologia?

\section{OBJECTIVOS}

Avaliar os benefícios e prejuízos dos biomarcadores de infecção em teste rápido para orientar o tratamento com antibióticos nos doentes que se apresentam com sintomas de IRA em contexto de cuidados de saúde primários, inde-

pendentemente da idade.

\section{METODOLOGIA}

Foram incluídos estudos controlados e aleatorizados (RCT) com doentes de cuidados de saúde primários com IRA que compararam a prescrição guiada por um biomarcador em teste rápido (gota de sangue capilar) com a prescrição guiada exclusivamente pela clínica. Foram incluídos ensaios aleatorizados com doentes individuais, bem como ensaios aleatorizados com grupos de doentes (RCT-clus-

\footnotetext{
1. Centro de Estudos de Medicina Baseada na Evidência. Faculdade de Medicina. Universidade de Lisboa. Lisboa. Portugal.

2. Centro Colaborador Português da Rede Cochrane Iberoamericana. Lisboa. Portugal.

3. Unidade de Farmacologia Clínica. Instituto de Medicina Molecular. Faculdade de Medicina. Universidade de Lisboa. Lisboa. Portugal.

Recebido: 02 de Dezembro de 2014 - Aceite: 02 de Dezembro de 2014 | Copyright @ Ordem dos Médicos 2014
} 
ter). Dois estudos tiveram patrocínio financeiro de fabricantes de antibióticos.

Apenas foram incluídos testes rápidos de uso genérico, sendo excluídos testes mais específicos como o do Streptococcus do grupo A ou o Monotest.

Foram realizadas pesquisas nas seguintes bases de dados: CENTRAL (2013, Edição 12), MEDLINE (de 1946 a Janeiro de 2014), EMBASE (de 2010 a Janeiro de 2014), CINAHL (de 1981 a Janeiro de 2014), Web of Science (de 1955 a Janeiro de 2014) e LILACS (de 1982 a Janeiro 2014). Dois revisores independentes coleccionaram os seguintes resultados: 1. impacto sobre o uso de antibióticos; 2. duração e recuperação da infecção; 3. complicações, incluindo o número de re-observações, internamentos e mortalidade; 4. satisfação do doente. Foi avaliado o risco de viés de todos os estudos incluídos e aplicada a classificação GRADE. Quando viável, foram realizadas estimativas quantitativas com recurso a meta-análise de efeitos aleatórios. Foram analisados ainda os resultados com um alto nível de heterogeneidade em subgrupos pré-especificados (RCTs individual e cluster).

\section{RESULTADOS}

O único biomarcador em teste rápido identificado como guia na prescrição de antibióticos foi a proteína C-reactiva (gota de sangue capilar, teste em $3 \mathrm{~min}$ ). Foram analisados 6 ensaios (3284 participantes; 134 crianças), com um risco de viés baixo a moderado.

Foi constatado um menor uso de antibióticos no grupo com prescrição guiada pela proteína C-reactiva em teste rápido $(631 / 1685 ; 37,4 \%)$ em contraponto com o grupo com a prescrição baseada exclusivamente na clínica (785/1599; $49 \%$ ). Contudo, a análise estatística obriga a uma interpretação cautelosa dos resultados uma vez que existe um alto nível de heterogeneidade e o teste de significância estatística para os $3 \mathrm{RCT}$ e para os $3 \mathrm{RCT}$-cluster pode não ser significativo [razão de risco (RR) 0,78 , intervalo de confiança (IC) $95 \%(0,66-0,92)$; estatística $\mathrm{I}^{2}=68 \%$ ]. O alto nível de heterogeneidade desaparece quando se analisa os subgrupos pré-planeados com base no desenho do estudo: para RCT-individual - RR 0,90; IC 95\%: 0,80-1,02; estatística $I^{2}=5 \%$; para RCT-cluster - RR 0,68; IC 95\%: 0,61-0,75; estatística $\mathrm{I}^{2}=0 \%$.

$\mathrm{Na}$ avaliação da recuperação clínica não houve diferenças significativas entre o grupo com prescrição antibiótica guiada pela proteína C-reactiva em teste rápido e o grupo com prescrição guiada exclusivamente pela clínica (melhoria substancial ao $7 .^{\circ}$ e $28 .^{\circ}$ dias de terapêutica ou necessidade de re-observação ao $28 .^{\circ}$ dia). Num dos estudos foi observado um aumento de hospitalizações no grupo onde foi usada a proteína C-reactiva, o que pode constituir uma descoberta casual, uma vez que se baseou apenas em alguns eventos. A mortalidade foi nula em ambos os grupos. Dado a imprecisão da estimativa do efeito principal, a qualidade da evidência foi classificada como moderada de acordo com a classificação GRADE.

\section{CONCLUSÕES}

Um biomarcador, como a proteína C-reativa, usado em teste rápido (gota de sangue capilar) para orientar o tratamento antibiótico das IRA em cuidados primários pode reduzir o uso de antibióticos, embora o grau de redução permaneça incerto. Todavia, tendo em conta os relatos dos doentes, a recuperação e a duração da doença não parecem ter sido alterados por esse efeito. Um possível aumento no número de internamentos nos doentes cuja monitorização da terapêutica é feita através da proteína C-reactiva em teste rápido é uma preocupação. É necessário uma estimativa de efeito mais precisa para avaliar os custos da intervenção e comparar o uso de um biomarcador em teste rápido com outras estratégias de poupança do uso de antibióticos.

\section{COMENTÁRIO}

A resistência aos antibióticos é uma preocupação global ${ }^{1}$. O uso indiferenciado de antibióticos, por exemplo no caso de infecções virais, parece estar relacionado com este efeito indesejado expondo o doente a riscos desnecessários².

Assim, o uso de um biomarcador de fase aguda (leucócitos, proteína C-reactiva, procalcitonina, entre outros) que nos permita guiar esta terapêutica em ambulatório reveste-se de um interesse particular. $\mathrm{O}$ uso de um teste rápido, à semelhança do que se faz na medição da glicémia capilar, parece ser promissor nesta área. Em todo o caso, nenhum destes parâmetros tem uma acuidade diagnóstica perfeita, obrigando sempre a uma integração na clínica apresentada e no doente. Efectivamente, objectiva-se uma redução do uso de antibióticos quando a prescrição é orientada pela proteína C-reactiva em teste rápido, contudo, não parece haver uma recuperação mais rápida nem uma menor duração da doença nos doentes em que este teste é realizado. O possível aumento do número de internamentos no grupo onde foi usada a proteína C-reactiva em teste rápido poderá estar relacionado com a identificação de casos com resposta inflamatória mais exuberante o que, integrado com a clínica, poder-se-á associar a casos de infecção bacteriana mais grave.

São necessários mais estudos com o uso de outros biomarcadores em teste rápido em comparação com o uso exclusivo da clínica e em comparação entre si.

\section{IMPLICAÇÕES PARA A PRÁTICA}

1. O uso de testes rápidos (gota de sangue capilar) para a proteína C-reactiva parece ser importante na identificação de casos de IRA em ambulatório que, em conjunto com a clínica, não necessitem de prescrição antibiótica, promovendo assim a redução do uso de antibióticos.

2. Dado o risco de falsos-negativos e falsos-positivos, a prescrição antibiótica nunca pode ser dissociada da clínica (história clínica e exame objectivo).

3. O aparente aumento do número de hospitalizações nos doentes com prescrição antibiótica guiada pela proteína C-reactiva em teste rápido deve constituir um sinal de alerta para a decisão individual e caso-a-caso ponderando riscos e benefícios da terapêutica. 
Tabela 1 - Resumo dos achados da comparação principal

Comparação do tratamento das infecções respiratórias agudas guiado por biomarcador em teste rápido com com o tratamento guiado pela clínica

Doente ou população: doente com infecção respiratória aguda

Alocação: cuidados de saúde primários

Intervenção: biomarcador (proteína C-reactiva) em teste rápido

Comparação: tratamento guiado pela clínica

\begin{tabular}{|c|c|c|c|c|c|c|}
\hline \multirow[b]{2}{*}{ Outcomes } & \multicolumn{2}{|c|}{$\begin{array}{l}\text { Riscos comparativos ilustrativos* } \\
\text { (IC } 95 \%)\end{array}$} & \multirow[b]{2}{*}{$\begin{array}{c}\text { Efeito (IC } \\
95 \%)\end{array}$} & \multirow[b]{2}{*}{$\begin{array}{c}\mathrm{N} .^{\circ} \text { de } \\
\text { participantes } \\
\text { (estudos) }\end{array}$} & \multirow[b]{2}{*}{$\begin{array}{l}\text { Qualidade } \\
\text { da evidência } \\
\text { (GRADE) }\end{array}$} & \multirow[b]{2}{*}{ Comentários } \\
\hline & $\begin{array}{c}\text { Risco } \\
\text { assumido } \\
\text { Tratamento } \\
\text { guiado pela } \\
\text { clínica }\end{array}$ & $\begin{array}{c}\text { Risco } \\
\text { correspondente } \\
\text { Proteína } \\
\text { C-reactiva }\end{array}$ & & & & \\
\hline $\begin{array}{l}\text { Mortalidade } \\
\text { (proteína C-reactiva) } \\
\text { Follow-up: } 28 \text { dias }\end{array}$ & - & - & - & $\begin{array}{r}3284 \\
(6)\end{array}$ & $\begin{array}{c}\text { ++++ } \\
\text { elevado }\end{array}$ & $\begin{array}{c}\text { Nenhum doente } \\
\text { faleceu nestes } \\
\text { estudos }\end{array}$ \\
\hline
\end{tabular}

\begin{tabular}{|c|c|c|c|c|c|}
\hline \multirow{4}{*}{$\begin{array}{l}\text { N. }{ }^{\circ} \text { de prescrições } \\
\text { de antibióticos } \\
\text { (proteína C-reactiva) } \\
\text { Pesquisa Index }\end{array}$} & $\begin{array}{l}\text { RCT-individual: população de } \\
\text { estudo } \\
467 \text { por } 1000\end{array}$ & $\begin{array}{l}\text { RR 0,90 } \\
(0,80 a\end{array}$ & 1309 & & \multirow[t]{2}{*}{ estatística $\mathrm{I}^{2}=5 \%$} \\
\hline & $(415$ a 529$)$ & 0,102 & (3) & & \\
\hline & RCT-cluster: população de estudo & RR 0.68 & 1975 & moderado & \multirow[b]{2}{*}{ estatística $\mathrm{I}^{2}=0 \%$} \\
\hline & $\begin{array}{ll}\mathbf{5 2 5} \text { por } 1000 & \mathbf{3 5 7} \text { por } 1000 \\
& (320 \text { a } 394)\end{array}$ & $\begin{array}{c}(0,61 \mathrm{a} \\
0,75)\end{array}$ & (3) & & \\
\hline \multirow{4}{*}{$\begin{array}{l}\text { N. }{ }^{\circ} \text { de prescrições } \\
\text { de antibióticos } \\
\text { (proteína C-reactiva) } \\
\text { Follow-up: } 28 \text { dias }\end{array}$} & $\begin{array}{r}\text { RCT-individual: população de } \\
\text { estudo } \\
542 \text { por } 1000\end{array}$ & RR 0,87 & & & \multirow[t]{2}{*}{ estatística $\mathrm{I}^{2}=7 \%$} \\
\hline & (467 a 635) & $1,02)$ & (2) & +++ & \\
\hline & RCT-cluster: população de estudo & & 211 & moderado $^{1}$ & \multirow{2}{*}{$\begin{array}{c}\text { estatística } I^{2}= \\
19 \%\end{array}$} \\
\hline & $\begin{array}{l}428 \text { por } 1000 \\
(321 \text { a } 572)\end{array}$ & $\begin{array}{c}(0,51 \mathrm{a} \\
0,91)\end{array}$ & & & \\
\hline \multirow{2}{*}{$\begin{array}{l}\text { Recuperação } \\
\text { clínica. N. de } \\
\text { participantes } \\
\text { com, pelo menos, } \\
\text { "recuperação } \\
\text { substancial" }\end{array}$} & $\begin{array}{l}\text { RCT-individual: população de } \\
\text { estudo }\end{array}$ & & 1264 & +++ & \multirow{2}{*}{ estatística $\mathrm{I}^{2}=0 \%$} \\
\hline & $\begin{array}{l}426 \text { por } 1000 \\
(385 \text { a } 472)\end{array}$ & $\begin{array}{c}(0,93 a \\
1,14)\end{array}$ & (3) & moderado $^{1}$ & \\
\hline $\begin{array}{l}\text { Recuperação } \\
\text { clínica } \\
\text { Follow-up: } 28 \text { dias }\end{array}$ & $\begin{array}{l}\begin{array}{c}\text { RCT-individual e RCT-cluster: } \\
\text { população de estudo } \\
713 \text { por } 1000 \\
758 \text { por } 1000\end{array} \\
\end{array}$ & $\begin{array}{c}\text { RR } 0.94 \\
(0,69 \text { a } \\
1,28)\end{array}$ & 527 & $\begin{array}{c}+++ \\
\text { moderado }^{1}\end{array}$ & estatística $\mathrm{I}^{2}=0 \%$ \\
\hline
\end{tabular}

*O risco assumido foi calculado com a mediana controlo do grupo de risco nos estudo. O risco correspondente (e o seu intervalo de confiança de $95 \%$ ) é baseado no risco assumido no grupo de comparação e o efeito relativo da intervenção (e o seu IC 95\%).

IC: intervalo de confiança; RR: razão de risco; RCT: Randomised Controlled Trial (ensaio controlado e aleatorizado)

Níveis de evidência do Grupo de Trabalho GRADE

Qualidade elevada: é pouco provável que investigação futura mude a nossa confiança no efeito estimado.

Qualidade moderada: é provável que investigação futura tenha um impacto importante na nossa confiança no efeito estimado e pode mudar essa estimativa.

Qualidade baixa: é muito provável que investigação futura tenha um impacto importante na nossa confiança no efeito estimado e mude a estimativa.

Qualidade muito baixa: há muitas incertezas acerca da estimativa

${ }^{1}$ Foi feita uma redução na qualidade de evidência GRADE para moderada uma vez que a heterogeneidade, embora bem explicada, gera imprecisão na estimativa de efeito principal. 


\section{REFERÊNCIAS}

1. Edmond MB, Wenzel RP. Organization for infection control. In: Mandell $\mathrm{GL}$, Bennett JE, Dolin R editors. Principles and practice of infectious diseases. $6^{\text {th }}$ ed. Philadelphia: Churchill Livingstone; 2005. p. 3323.
2. Magill SS, Edwards JR, Bamberg W, Beldavs ZG, Dumyati G, Kainer MA, et al. Multistate point-prevalence survey of health care-associated infections. N Engl J Med. 2014;370:1198-208.

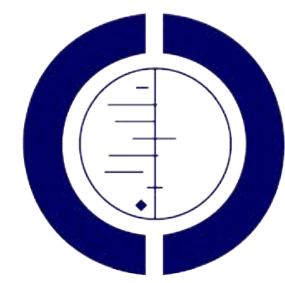

THE COCHRANE COLLABORATION 


\section{Análise da Revisão Cochrane: Biomarcadores em Testes Rápidos para Guiar a Prescrição de Antibióticos em Doentes com Infecções Respiratórias Agudas nos Cuidados de Saúde Primários. Cochrane Database Syst Rev. 2014,11:CD010130}

Acta Med Port 2014:27:677-680

Publicado pela Acta Médica Portuguesa, a Revista Científica da Ordem dos Médicos

Av. Almirante Gago Coutinho, 151

1749-084 Lisboa, Portugal.

Tel: +351218428 215

E-mail: submissao@actamedicaportuguesa.com

www.actamedicaportuguesa.com

ISSN:0870-399X | e-ISSN: 1646-0758

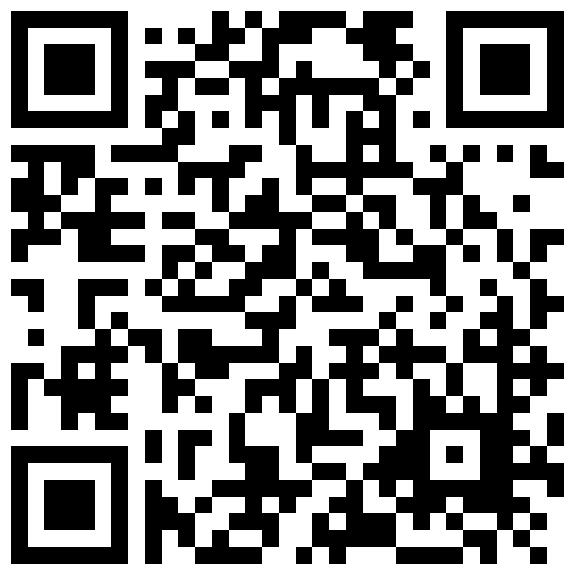

